\title{
Ethyl-cellulose rumen-protected methionine alleviates inflammation and oxidative stress and improves neutrophil function during the periparturient period and early lactation in Holstein dairy cows
}

\author{
F. Batistel, ${ }^{*}$ J. M. Arroyo, ${ }^{\star} †$ C. I. M. Garces, ${ }^{*}$ E. Trevisi,‡ C. Parys,§ M. A. Ballou,\# F. C. Cardoso, ${ }^{\star}$ \\ and J. J. Loor*1 \\ ${ }^{*}$ Department of Animal Sciences and Division of Nutritional Sciences, University of Illinois, Urbana 61801 \\ †Departamento de Nutrición Animal, Instituto de Producción Animal, Facultad de Veterinaria, Universidad de la Republica, Ruta 1 km 42.5 \\ 80100, San José, Uruguay \\ †lstituto di Zootecnica, Facoltà di Scienze Agrarie Alimentari ed Ambientali, Università Cattolica del Sacro Cuore, Piacenza 29122, Italy \\ §Evonik Nutrition \& Care GmbH, 63457 Hanau-Wolfgang, Germany \\ \#Department of Animal Sciences, Texas Tech University, Lubbock 79409
}

\begin{abstract}
The periparturient period is the most critical phase in the productive cycle of dairy cows and is characterized by impairment of the immune system. Our objective was to evaluate the effect of feeding ethylcellulose rumen-protected methionine (RPM) starting at $\mathrm{d}-28$ from expected parturition through $60 \mathrm{~d}$ in milk on biomarkers of inflammation, oxidative stress, and liver function as well as leukocyte function. Sixty multiparous Holstein cows were used in a block design and assigned to either a control or the control plus ethyl-cellulose RPM (Mepron, Evonik Nutrition \& Care $\mathrm{GmbH}$ ). Mepron was supplied from -28 to $60 \mathrm{~d}$ in milk at a rate of $0.09 \%$ and $0.10 \%$ dry matter during the prepartum and postpartum period. That rate ensured that the ratio of Lys to Met in the metabolizable protein was close to 2.8:1. Blood samples from 15 clinically healthy cows per treatment were collected at $\mathrm{d}-30,-14,1,7,21,30$, and 60 and analyzed for biomarkers of liver function, inflammation, and oxidative stress. Neutrophil and monocyte function in whole blood was measured in vitro at $-14,1,7,21$, and 30 $\mathrm{d}$ in milk. The statistical model included the random effect of block and fixed effect of treatment, time, and its interaction. Compared with control, ethyl-cellulose RPM increased plasma cholesterol and paraoxonase after parturition. Among the inflammation biomarkers measured, ethyl-cellulose RPM led to greater albumin (negative acute-phase protein) and lower haptoglobin than control cows. Although concentration of IL-1 $\beta$ was not affected by treatments, greater IL- 6 concentration was detected in response to ethyl-cellulose RPM. Cows supplemented with ethyl-cellulose RPM had greater
\end{abstract}

Received May 18, 2017.

Accepted August 24, 2017.

${ }^{1}$ Corresponding author: jloor@illinois.edu plasma concentration of ferric-reducing antioxidant power, $\beta$-carotene, tocopherol, and total and reduced glutathione, whereas reactive oxygen metabolites were lower compared with control cows. Compared with control, ethyl-cellulose RPM enhanced neutrophil phagocytosis and oxidative burst. Overall, the results indicate that ethyl-cellulose RPM supply to obtain a Lys-to-Met ratio of 2.8:1 in the metabolizable protein during the periparturient period and early lactation is an effective approach to help mitigate oxidative stress and inflammation as well as enhance liver and neutrophil function in dairy cows.

Key words: immunometabolism, methionine, transition period

\section{INTRODUCTION}

The periparturient period is the most critical phase in the productive life of high-producing dairy cows, and is characterized by the highest incidence and severity of both metabolic and infectious diseases (Bertoni et al., 2008; Trevisi et al., 2012; Sordillo, 2016). The inflammatory response can be activated by infection or injury, as well as tissue stress and malfunction in the absence of infection or evident tissue damage (Chovatiya and Medzhitov, 2014; Trevisi et al., 2016). The classic initiators of inflammation, infection and tissue injury, trigger the recruitment of leukocytes to the damaged or contaminated tissue, and immune cell function is fundamental for the efficiency and duration of the inflammatory process (Medzhitov, 2008). In cases of tissue stress or malfunction, the inflammatory response is mainly dependent on tissue-resident macrophages and, based on human disease models, it is responsible for chronic inflammatory conditions (Medzhitov, 2008). The inflammatory process triggers the acute-phase response, which alters liver function at least in part by switching to synthesis of positive acute-phase proteins 
(e.g., ceruloplasmin, haptoglobin) instead of negative acute-phase proteins (e.g., albumin) in an attempt to reestablish homeostasis (Cray et al., 2009).

Most dairy cows in early lactation experience a prolonged imbalance between production of free radicals and their elimination by antioxidants (Sordillo and Aitken, 2009), often causing cellular damage followed by a chronic inflammatory response. Oxidative stress around calving also can be a consequence of an infection-induced inflammatory response (Trevisi et al., 2016). Thus, the inflammatory events that afflict cows during early lactation are associated with physiological stressful conditions and the metabolic overload of the liver to meet the nutrient requirements for maintenance and milk synthesis (Trevisi et al., 2016).

It is well established that transition cows experience negative energy and protein balance (Drackley, 1999), and that nutrition plays a critical role in supporting the immune system (Bertoni et al., 2015; Sordillo, 2016). Methionine is the first-limiting AA in dairy cows (NRC, 2001), and recent data underscored its immunometabolic potential (Osorio et al., 2014; Sun et al., 2016; Zhou et al., 2016a). In the liver, methionine can be metabolized to S-adenosyl methionine, a fundamental methyl donor, as well as phosphatidylcholine, which is a main constituent of very low density lipoproteins. Furthermore, methionine metabolism can generate intracellular antioxidants such as glutathione (GSH) and taurine (Brosnan and Brosnan, 2006). Therefore, our general hypothesis was that feeding ethyl-cellulose rumen-protected methionine (RPM) to obtain a Lysto-Met ratio of 2.8:1 in the MP from $\mathrm{d}-28$ relative to the expected parturition to 60 DIM would help reduce the inflammatory and oxidative stress status and enhance liver function and leukocyte function in the cow.

\section{MATERIALS AND METHODS}

\section{Animal Housing and Care}

The Institutional Animal Care and Use Committee at the University of Illinois (Urbana; protocol \#14270) approved all experimental procedures. All cows were housed in a freestall system equipped with the Calan gate system (American Calan Inc., Northwood, NH) during the prepartum period. After parturition, all cows were housed in tiestalls. Cows were fed once daily (1300 h) at $120 \%$ of expected intake, and milked 3 times daily (0600, 1400, and $2200 \mathrm{~h})$.

\section{Design and Treatments}

Additional details of the experimental design have been described previously (Batistel et al., 2017). Briefly,
60 multiparous Holstein cows from the University of Illinois Dairy Research Farm were used in a randomized, complete, unbalanced block design experiment with 30 cows per treatment. The data presented herein is from a subset of cows. Cows were blocked by the expected parturition day, and the blocks were balanced by parity, previous 305-d milk yield, and BCS. The BCS used to block cows was measured at $-30 \mathrm{~d}$ before parturition using the scale 1 to $5(1=$ thin, $5=$ fat; scale in 0.25 increments). Cows within each block were randomly assigned to 1 of the 2 treatments. Treatment diets were a control diet without Met supplementation or the control diet plus ethyl-cellulose RPM (Mepron, Evonik Nutrition \& Care GmbH, Hanau-Wolfgang, Germany). Ethylcellulose RPM was supplied from -28 to $60 \mathrm{~d}$ relative to parturition at a rate of 0.09 and $0.10 \%$ of the DMI of the previous day during the prepartum and postpartum period. Mepron is a commercial rumen-protected source of DL-Met that resists ruminal degradation through an ethyl-cellulose film coating. Pellets measure $1.8 \times 3 \mathrm{~mm}$ and contain $85 \%$ DL-Met. The intestinal digestibility coefficient and rumen bypass of Mepron are 90 (Schwab, 1995) and 80\% (Overton et al., 1996), respectively; therefore, per $10 \mathrm{~g}$ of Mepron, the cows received $6.1 \mathrm{~g}$ of Met available for absorption. The target values of Met supply were based on recent experiments demonstrating a benefit in terms of production performance and health of supplementing rumen-protected Met to achieve a Lys-to-Met ratio close to 2.8:1 during the prepartum and postpartum periods (Osorio et al., 2013; Zhou et al., 2016b). The Lys-to-Met ratio in the control group was close to $3.7: 1$ during the prepartum and postpartum periods. During the far-off period (from -45 to -29 d), all cows received the same diet $(1.33 \mathrm{Mcal} / \mathrm{kg}$ of DM and $13.9 \% \mathrm{CP}$ ) with no RPM. The basal close-up (from $-28 \mathrm{~d}$ to parturition), fresh (from 1 to $30 \mathrm{~d}$ ), and high-production (from 31 to $60 \mathrm{~d}$ ) diets contained 1.47 $\mathrm{Mcal} / \mathrm{kg}$ of $\mathrm{DM}$ and $15.3 \% \mathrm{CP}, 1.67 \mathrm{Mcal} / \mathrm{kg}$ of $\mathrm{DM}$ and $17.7 \% \mathrm{CP}$, and $1.61 \mathrm{Mcal} / \mathrm{kg}$ of DM and $17.4 \% \mathrm{CP}$, respectively. The ingredient and nutrient composition of the diets fed are reported in Table 1 and 2. All diets were formulated to meet cow predicted requirements according to NRC (2001).

\section{Blood and Liver Sample Collection and Biomarker Analysis}

Blood was sampled from the coccygeal vessel before the feeding in 15 cows per treatment at $\mathrm{d}-30,-14,1$, $7,21,30$, and $60 \mathrm{~d}$ relative to calving date. This subset of cows was chosen based on absence of clinical disease and enrollment for liver biopsy. Incidence of ketosis, lameness, mastitis, milk fever, retained placenta, and displaced abomasum did not differ with treatment (Ba- 
tistel et al., 2017). Liver biopsy cows were chosen based on previous 305-d milk yield, BCS, and absence of clinical disease. Samples were collected into evacuated tubes (BD Vacutainer, BD and Co., Franklin Lakes, NJ) containing lithium heparin. After blood collection, samples were placed on ice until centrifugation $(\sim 40$ min) or the neutrophil function assay. Plasma was obtained by centrifugation at $2,000 \times g$ for $30 \mathrm{~min}$ at $4^{\circ} \mathrm{C}$. Aliquots of plasma were frozen $\left(-80^{\circ} \mathrm{C}\right)$ until further analysis.

Liver was sampled via puncture biopsy (Dann et al., 2005) from 10 cows per treatment. Samples were collected from the same cows under local anesthesia at approximately $0800 \mathrm{~h}$ on $\mathrm{d}-21,-10,1$, and 10 relative to parturition. Liver was frozen immediately in liquid $\mathrm{N}$ and stored $\left(-80^{\circ} \mathrm{C}\right)$ until further analysis.

Plasma samples were analyzed for albumin (catalog no. 0018250040), aspartate aminotransferase (catalog no. 0018257540), bilirubin (catalog no. 0018254640), and cholesterol (catalog no. 0018250540) with kits purchased from Instrumentation Laboratory Spa (Werfen Co., Milan, Italy) using the clinical auto-analyzer (ILAB 650, Instrumentation Laboratory). Haptoglobin, ceruloplasmin, and paraoxonase were determined by adapting the methods of Owen et al. (1960) and Skinner et al. (1991), Sunderman and Nomoto (1970), and Ferré et al. (2002), respectively, to the ILAB 650 conditions. Reactive oxygen metabolites (ROM) were ana-

Table 1. Ingredient and nutrient composition of far-off (from -45 to $-29 \mathrm{~d}$ ), close-up (from $-28 \mathrm{~d}$ to parturition), fresh (from 1 to 30 DIM) and high-producing (from 31 to 60 DIM) diets

\begin{tabular}{|c|c|c|c|c|}
\hline \multirow[b]{2}{*}{ Ingredient, $\%$ of $\mathrm{DM}$} & \multicolumn{4}{|c|}{ Diet } \\
\hline & Far-off & Close-up & Fresh & High-producing \\
\hline Alfalfa haylage & - & 6.55 & 7.81 & 10.8 \\
\hline Corn silage & 34.7 & 26.6 & 31.0 & 31.9 \\
\hline Wheat straw & 33.7 & 26.5 & 3.25 & - \\
\hline Corn grain, ground, dry & - & 12.6 & 22.21 & 20.7 \\
\hline Cottonseed & - & - & 2.17 & 1.83 \\
\hline Molasses, beet sugar & - & 4.03 & 5.50 & 4.51 \\
\hline Soybean hulls & 15.7 & 3.46 & 4.25 & 9.96 \\
\hline Soybean meal, $48 \% \mathrm{CP}$ & 12.0 & 7.83 & 10.1 & 7.98 \\
\hline Expeller soybean meal $^{1}$ & - & 5.80 & 5.16 & 5.17 \\
\hline Protein supplement $^{2}$ & - & 0.78 & 1.81 & 1.58 \\
\hline Urea & 0.46 & 0.59 & 0.39 & 0.40 \\
\hline Soychlor $^{3}$ & - & 1.23 & - & - \\
\hline Saturated fat supplement ${ }^{4}$ & - & - & 2.25 & 2.14 \\
\hline Limestone & - & - & 1.41 & 0.96 \\
\hline Salt & 0.40 & - & 0.02 & 0.04 \\
\hline Dicalcium phosphate & 0.50 & 0.52 & 1.17 & 0.92 \\
\hline Magnesium oxide & - & - & 0.08 & 0.04 \\
\hline Magnesium sulfate & 1.90 & 2.08 & 0.02 & - \\
\hline Sodium bicarbonate & - & - & 0.84 & 0.59 \\
\hline Mineral vitamin $\operatorname{mix}^{5}$ & 0.40 & 0.17 & 0.17 & 0.20 \\
\hline Vitamin $\mathrm{A}^{6}$ & - & 0.03 & 0.02 & 0.02 \\
\hline Vitamin $D^{7}$ & - & 0.03 & - & - \\
\hline Vitamin $E^{8}$ & 0.40 & 0.60 & - & - \\
\hline Biotin $^{9}$ & - & 0.70 & 0.42 & 0.32 \\
\hline Monensin $^{10}$ & 0.01 & - & - & - \\
\hline Ethyl-cellulose RPM ${ }^{11}$ & - & 0.09 & 0.10 & 0.10 \\
\hline
\end{tabular}

${ }^{1}$ SoyPlus, West Central Soy, Ralston, IA.

${ }^{2}$ ProVAAl AADvantage, Perdue AgriBusiness, Salisbury, MD.

${ }^{3}$ West Central Soy.

${ }^{4}$ Energy Booster 100, Milk Specialties Global, Eden Prairie, MN.

${ }^{5}$ Contained a minimum of $5 \% \mathrm{Mg}, 10 \% \mathrm{~S}, 7.5 \% \mathrm{~K}, 2.0 \% \mathrm{Fe}, 3.0 \% \mathrm{Zn}, 3.0 \% \mathrm{Mn}, 5,000 \mathrm{mg}$ of Cu/kg, $250 \mathrm{mg}$ of I/kg, $40 \mathrm{mg}$ of $\mathrm{Co} / \mathrm{kg}, 150 \mathrm{mg}$ of Se $/ \mathrm{kg}, 2,200 \mathrm{kIU}$ of vitamin $\mathrm{A} / \mathrm{kg}, 660 \mathrm{kIU}$ of vitamin $\mathrm{D}_{3} / \mathrm{kg}$, and 7,700 IU of vitamin $\mathrm{E} / \mathrm{kg}$.

${ }^{6}$ Contained $30,000 \mathrm{kIU} / \mathrm{kg}$.

${ }^{7}$ Contained 5,000 kIU/kg.

${ }^{8}$ Contained 44,000 kIU/kg.

${ }^{9} \mathrm{ADM}$ Animal Nutrition, Quincy, IL.

${ }^{10}$ Rumensin, Elanco Animal Health, Greenfield, IN.

${ }^{11}$ Ethyl-cellulose rumen-protected methionine, Evonik Nutrition \& Care GmbH, Hanau-Wolfgang, Germany. Only added in the treatment group. 
RUMEN-PROTECTED METHIONINE AND IMMUNOMETABOLISM

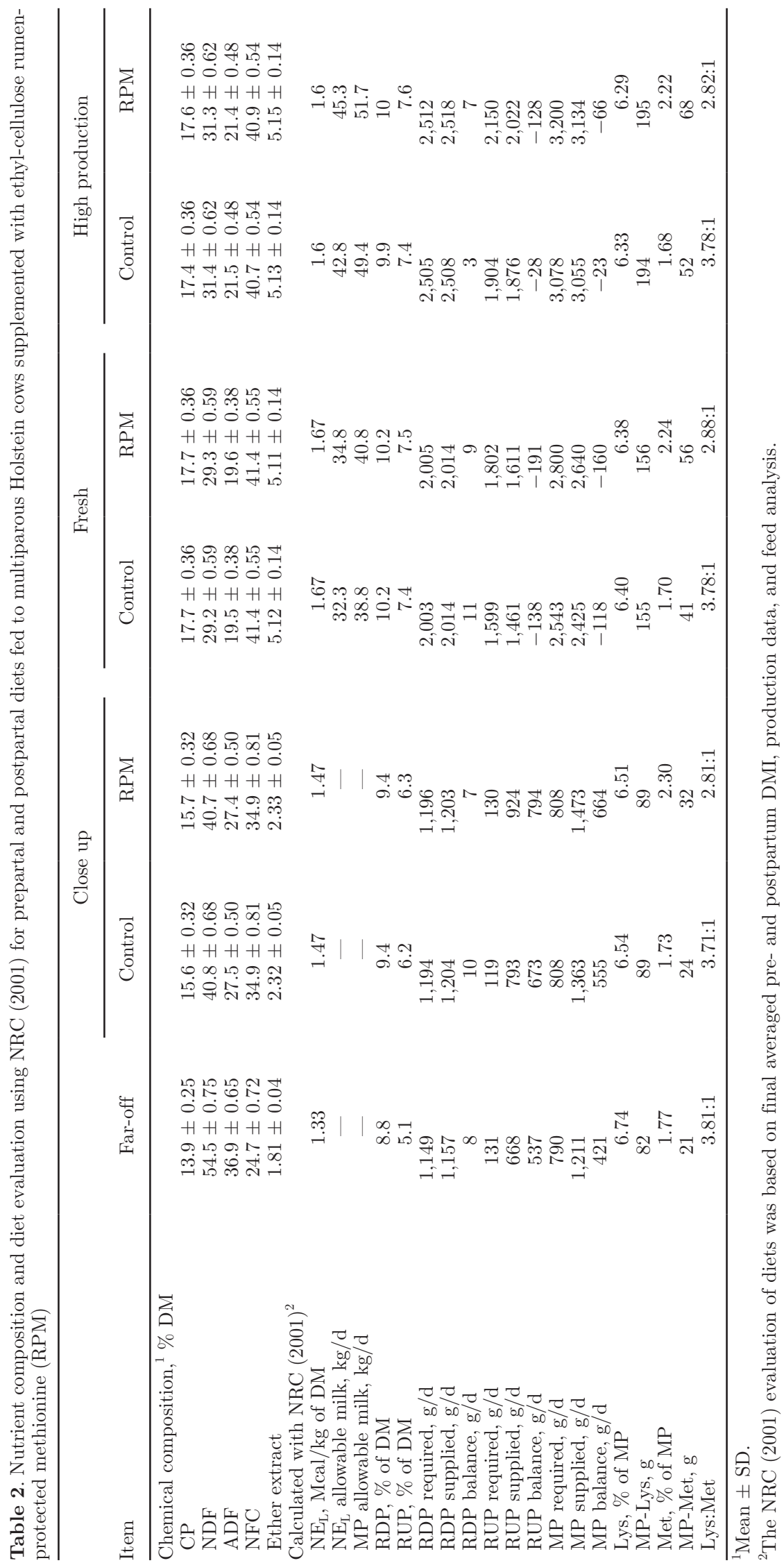


lyzed with the d-ROMs-test (cod. MC002) purchased from Diacron (Grosseto, Italy). Total antioxidant capacity was assessed as ferric-reducing antioxidant power (FRAP) using the colorimetric method of Benzie and Strain (1996). Myeloperoxidase was determined as previously-described (Bionaz et al., 2007), via colorimetry based on the reaction of MPO contained in the plasma sample with hydrogen peroxide, which forms $\mathrm{H}_{2} \mathrm{O}$ and $\mathrm{O}^{-}$; the o-dianisidine dihydrochloride, and electron donor, reacts with the $\mathrm{O}^{-}$, releasing $\mathrm{H}_{2} \mathrm{O}$ and a colored compound. Plasma retinol and tocopherol were extracted with hexane and analyzed by reverse-phase HPLC using Spherisorb ODS-2, $3 \mu \mathrm{m}$, in a $150 \times 4.6$ mm column (Alltech, Deerfield, IL); a UV detector set at 325 (for retinol) or $290 \mathrm{~nm}$ (for tocopherol); and 80:20 methanol:tetrahydrofuran as the mobile phase. Bovine IL-1 $\beta$ (Cat. No. ESS0027; Thermo Scientific, Rockford, IL) and IL-6 (Cat. No. ESS0029; Thermo Scientific) plasma concentrations were determined using commercial kits.

The simultaneous phagocytosis capacity and oxidative burst activity of peripheral monocytes and neutrophils was determined upon challenge with enteropathogenic bacteria (Escherichia coli 0118:H8) exactly as described previously (Zhou et al., 2016a). Data are reported as percentages of CD14- and CH138A-positive cells with phagocytosis and oxidative burst capability.

Liver tissue total and oxidized GSH were measured using a commercial kit (Cat. No. NWH-GSH01; Northwest Life Science Specialties LLC, Vancouver, WA). Reduced GSH was calculated as reduced GSH = total GSH - oxidized GSH.

\section{Statistical Analysis}

Data were analyzed using the MIXED procedure of SAS v.9.4 (SAS Institute Inc., Cary, NC) according to the following model with repeated measures:

$$
Y_{i j k l}=\mu+b_{i}+M_{j}+T_{k}+M T_{j k}+c_{l}\left(b_{i}\right)+e_{i j k l},
$$

where $Y_{i j k l}=$ dependent, continuous variable, $\mu=$ overall mean, $b_{i}=$ random effect of block ( $i=1$ to 7$), M_{j}=$ fixed effect of treatment ( $j=$ control vs. ethyl-cellulose $\mathrm{RPM}), T_{k}=$ fixed effect of time (day or week), $M T_{j k}=$ interaction between treatment and time, $c_{l}\left(b_{i}\right)=$ random effect of cow within block, and $e_{i j k l}=$ residual error. The covariates for parity, previous 305-d milk yield, and BCS at $-30 \mathrm{~d}$ relative to parturition were kept in the model for all variables when significant. For the blood analysis, plasma data at $-30 \mathrm{~d}$ relative to parturition were included as a covariate when significant. Unless otherwise specified, first-order autoregressive was the covariate structure used for analysis because it resulted in the lowest Bayesian information criterion for most of the variables measured. Normality of the residuals was checked with normal probability and box plots. Data were $\log _{2}$-scale transformed if needed to comply with normal distribution of residuals. For ease of interpretation, the tables and graphs contain the $\log _{2}$ backtransformed means that resulted from the statistical analysis. Significance was determined at $P \leq 0.05$ and tendencies at $P \leq 0.10$.

\section{RESULTS AND DISCUSSION}

\section{Biomarkers of Liver Function}

During the transition to lactation, the metabolic activity of liver increases substantially in large part to help meet the nutrient requirements necessary for milk synthesis. The glucose requirement has been estimated to be $1.2 \mathrm{~kg} / \mathrm{d}$ at $3 \mathrm{wk}$ before calving and increases to $3 \mathrm{~kg} / \mathrm{d}$ as a result of hepatic gluconeogenesis at $3 \mathrm{wk}$ postpartum when milk production is around $36 \mathrm{~kg} / \mathrm{d}$ (Reynolds et al., 2003; Aschenbach et al., 2010). The liver also is essential for the metabolism of nonesterified fatty acids taken up due to the mobilization of adipose depots (Drackley et al., 2001). Thus, cows with optimal liver function are able to overcome the peripartal period more efficiently and exhibit signs of reduced inflammation, oxidative, and metabolic stress (Bionaz et al., 2007; Bertoni et al., 2008).

During the periparturient period, cows experience several stressful events including regrouping, dietary changes, parturition, and the onset of lactation (Trevisi et al., 2016). Under normal physiological conditions the liver synthesizes and releases proteins and enzymes into the blood, which can be used as biomarkers of liver function (Ferré et al., 2002; Bertoni et al., 2008). Main effects of ethyl-cellulose RPM, time, and interactions on liver function biomarkers are reported in Table 3. Ethyl-cellulose RPM increased plasma paraoxonase $(P$ $<0.01)$ and cholesterol $(P=0.02)$ after parturition (Figure 1), but aspartate aminotransferase and bilirubin were not affected by treatments $(P \geq 0.15)$.

Similar to our results, a recent study reported that, although basal plasma paraoxonase concentration decreased soon after parturition, cows supplemented with RPM during the peripartal period had greater liver synthesis of paraoxonase during the postpartum period (Zhou et al., 2016a). Although the higher plasma concentrations of cholesterol in the ethyl-cellulose RPM group reflected in part the greater DMI of those cows, its response together with the higher plasma concentrations of paraoxonase and lower $\gamma$-glutamyl transferase 
(Batistel et al., 2017) indicate that ethyl-cellulose RPM supplementation was able to ameliorate liver function during the postpartum period.

\section{Biomarkers of Inflammation}

Main effects of ethyl-cellulose RPM, time, and interactions on inflammation biomarkers are reported in Table 3. The inflammatory process is a well-conserved mechanism to overcome adverse stimuli and restore homeostasis. Dairy cows experience some degree of inflammation after parturition (Bertoni et al., 2004; Humblet et al., 2006; Sordillo, 2016). A retrospective study, where cows were classified by degree of liver inflammation based on plasma concentrations of acutephase proteins, indicated that inflammation increases the risk of transition disorders and impairs animal performance during early lactation (Bertoni et al., 2008). In a recent review, Bradford et al. (2015) proposed that the duration of the inflammatory process rather than its complete avoidance is one of the normal adaptations to lactation; therefore, measuring the consequences of inflammatory conditions in the peripartum period is of importance (Trevisi et al., 2016).

Among the inflammation biomarkers measured, compared with control, ethyl-cellulose RPM led to greater
$(P<0.01)$ albumin (negative acute-phase protein) and lower haptoglobin $(P<0.01 ;$ Figure 2$)$. This marked decrease in the concentration of haptoglobin by $\mathrm{d} 21$ postpartum in ethyl-cellulose RPM-supplemented cows indicates they were able to better control the inflammatory response. Additionally, the higher concentration of plasma albumin, as well as cholesterol and paraoxonase, which are also biomarkers of anti-inflammatory responses, in ethyl-cellulose RPM cows supports the idea that they were under a less pronounced inflammatory state (Trevisi et al., 2011; Grossi et al., 2013). Myeloperoxidase tended $(P=0.15)$ to be higher in the ethyl-cellulose RPM group compared with control cows. Ceruloplasmin and alkaline phosphatase were not affected by ethyl-cellulose RPM supply. For cytokines, a main effect with greater IL-6 in ethyl-cellulose RPMsupplemented cows was detected $(P=0.05)$, whereas the concentration of IL-1 $\beta$ was not affected $(P>0.10)$ by ethyl-cellulose RPM supply. Because IL-6 has proinflammatory and anti-inflammatory properties (Xing et al., 1998; Scheller et al., 2011), the increased albumin and decreased haptoglobin profiles suggest that in ethyl-cellulose RPM cows it might have exerted an anti-inflammatory effect. A similar pattern of IL-6 was observed when periparturient cows received a different source of RPM (Zhou et al., 2016a).

Table 3. Effects of ethyl-cellulose rumen-protected methionine (RPM) supplementation to multiparous Holstein dairy cows during the close-up (from $-28 \mathrm{~d}$ to parturition), fresh (from 1 to $30 \mathrm{DIM}$ ), and high-producing (from 31 to $60 \mathrm{DIM}$ ) periods on plasma biomarkers of liver function, inflammation and oxidative stress

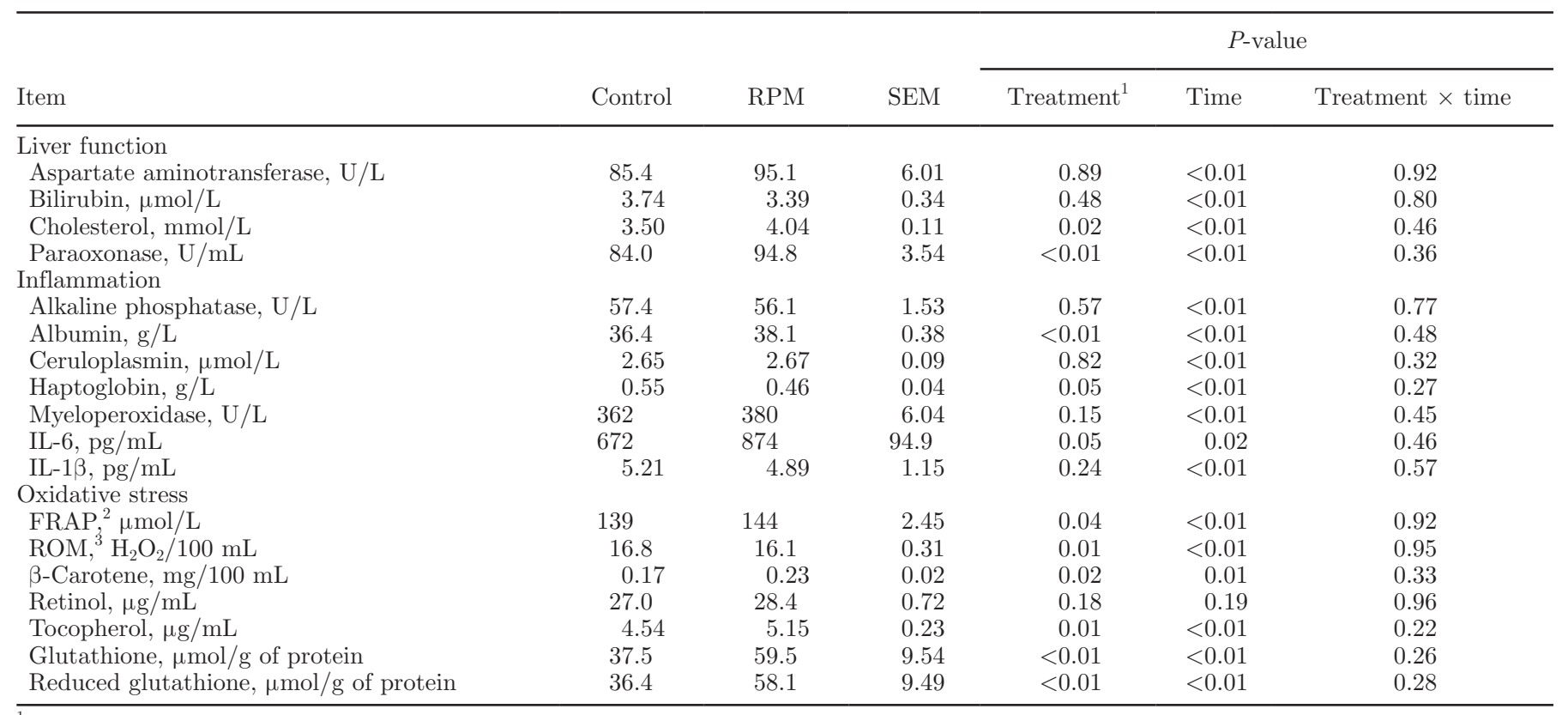

${ }^{1}$ Ethyl-cellulose rumen-protected methionine effect.

${ }^{2}$ Ferric-reducing ability of plasma.

${ }^{3}$ Reactive oxygen metabolites. 
A

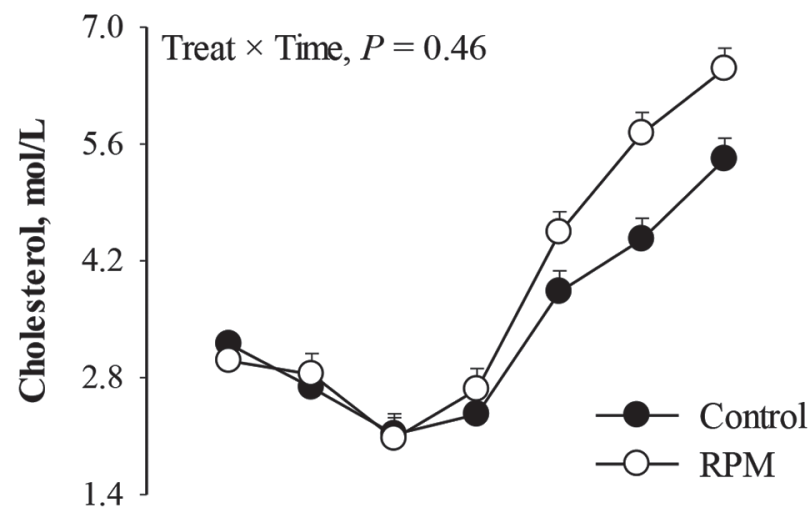

B

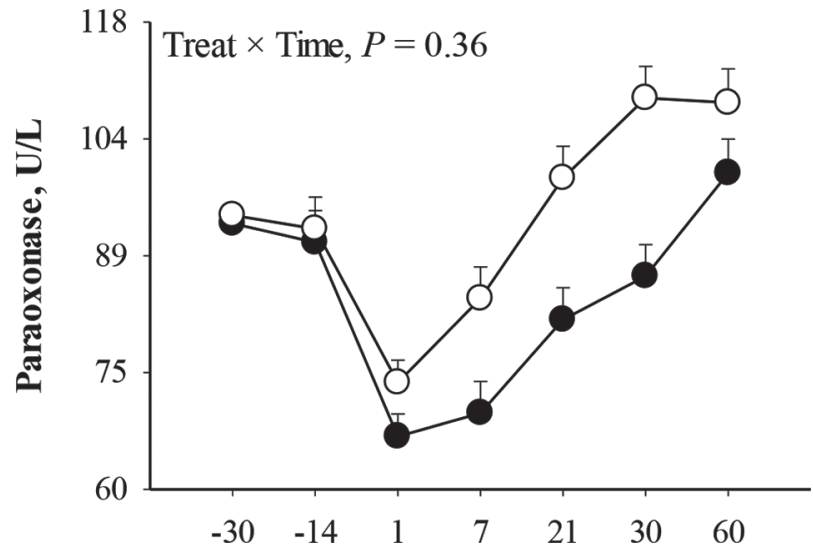

Day relative to parturition

Figure 1. Effect of ethyl-cellulose rumen-protected methionine (RPM) supplementation to multiparous Holstein cows from -28 through 60 DIM on plasma biomarkers of liver function $(\mathrm{A}=$ cholesterol; $\mathrm{B}=$ paraoxonase). Values represent the means \pm SEM. The data from $\mathrm{d}-30$ were included as reference. Treat $=$ treatment.

\section{Biomarkers of Oxidative Stress}

Main effects of ethyl-cellulose RPM, time, and interactions on biomarkers of oxidative stress are reported in Table 3. Compared with control, cows supplemented with ethyl-cellulose RPM had greater plasma concentration of $\operatorname{FRAP}(P=0.04)$ and lower concentration of $\operatorname{ROM}(P=0.01$; Figure 3$)$. The higher plasma concentration of ROM in the postpartum period was expected because, in conditions of high metabolic demand, the production of free radicals is enhanced partly due to the increase in oxygen requirements (Sordillo and Aitken, 2009). Excessive and rapid production of free radicals can cause an imbalance between ROM concentrations and antioxidant mechanisms, often leading to an increase in oxidative stress. The lower plasma concentration of ROM in cows supplemented with ethyl-cellulose RPM indicated less pronounced oxidative stress status, which agrees with the profiles of inflammation biomarkers.
A

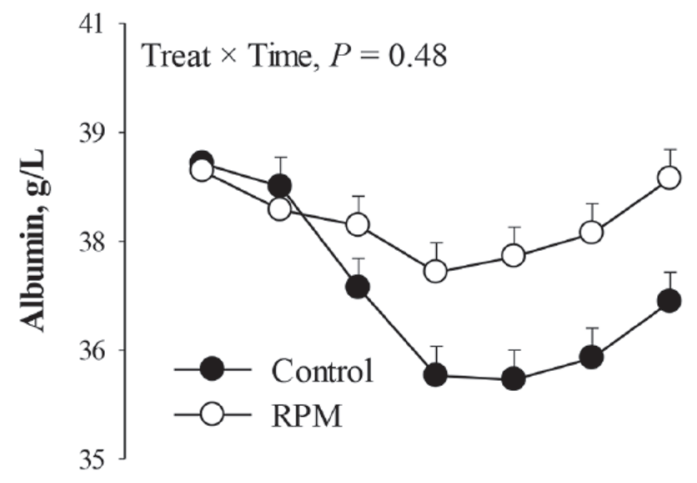

B

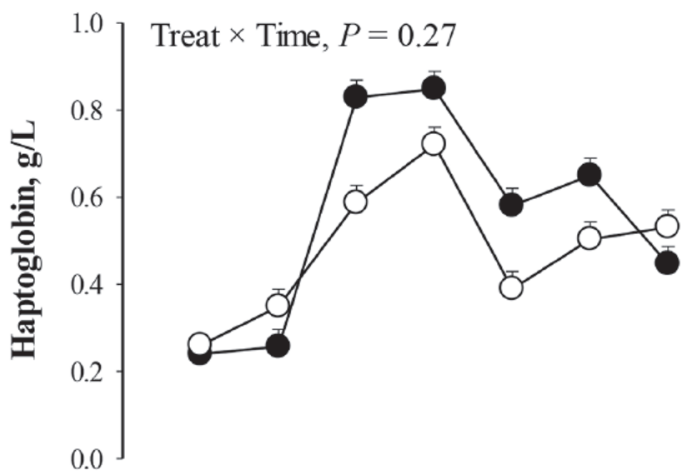

C

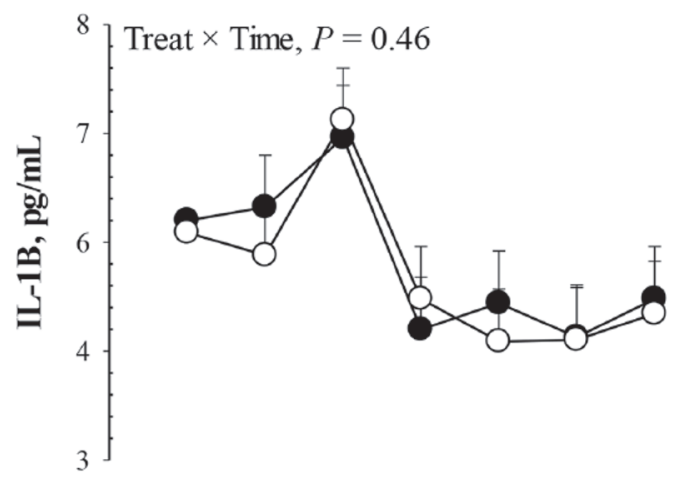

D

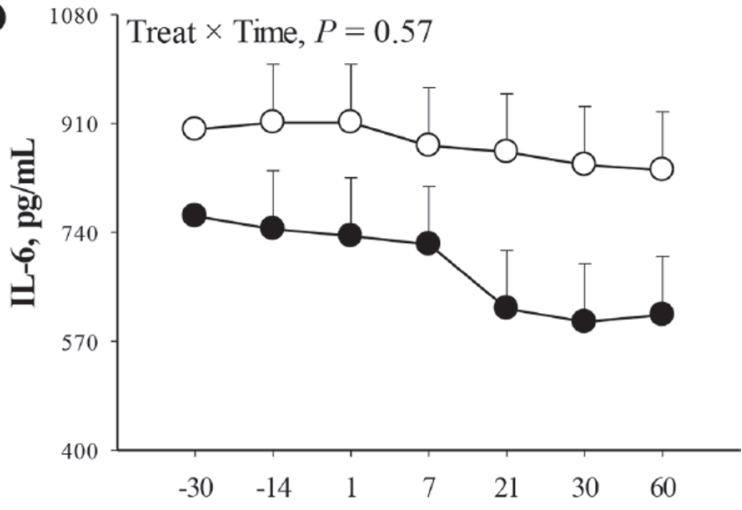

Day relative to parturition

Figure 2. Effect of ethyl-cellulose rumen-protected methionine (RPM) supplementation to multiparous Holstein cows from -28 through 60 DIM on plasma biomarkers of inflammation $(\mathrm{A}=$ albumin; $\mathrm{B}=$ haptoglobin; $\mathrm{C}=\mathrm{IL}-1 \beta ; \mathrm{D}=\mathrm{IL}-6)$. Values represent the means \pm SEM. The data from $d-30$ were included as reference. Treat $=$ treatment. 
Compared with controls, cows supplemented with ethyl-cellulose RPM had greater plasma concentrations of $\beta$-carotene and tocopherol $(P<0.02$; Figure 3$)$. These results partly reflect the greater DMI in RPM cows during the postpartum period (Batistel et al.,
2017). The greater concentrations of those vitamins, together with greater plasma concentration of FRAP, is positively associated with antioxidant activity (Benzie and Strain, 1996; Trevisi et al., 2011). Retinol concentration was not different between groups $(P=0.18)$.
A

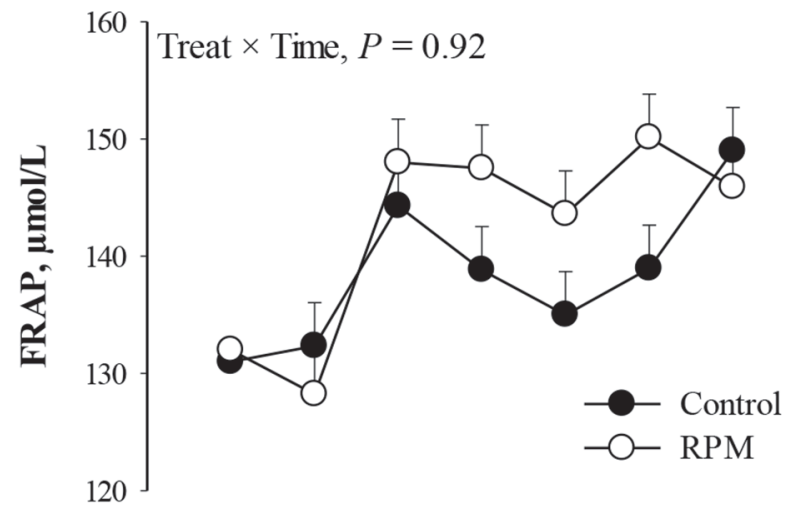

B

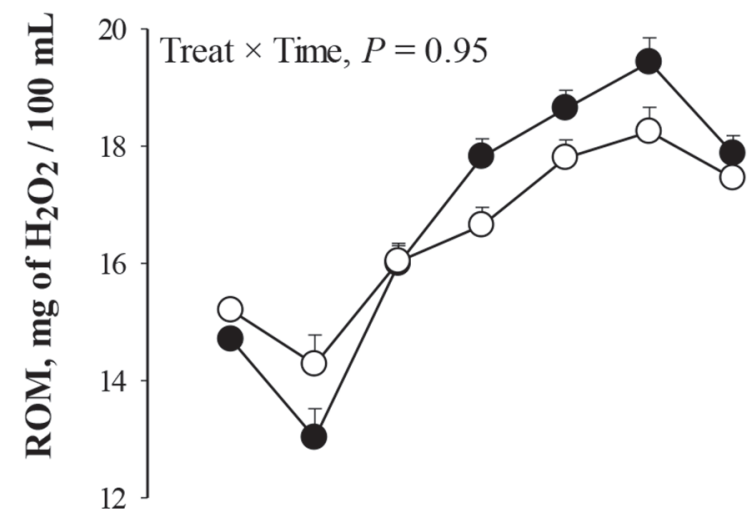

C

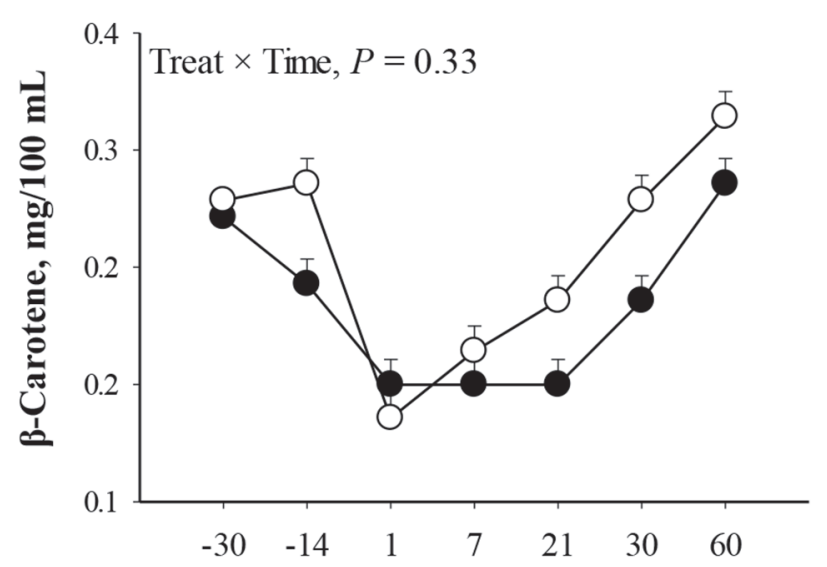

Day relative to parturition
D

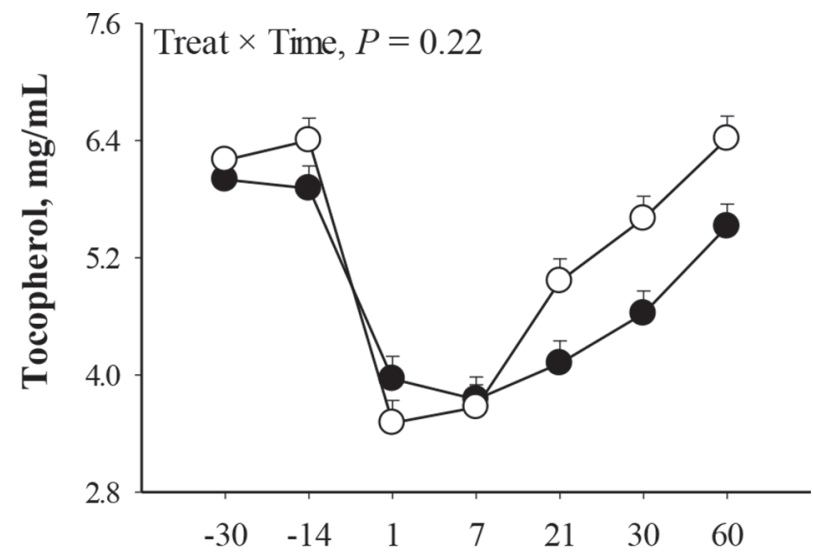

$\mathbf{E}$

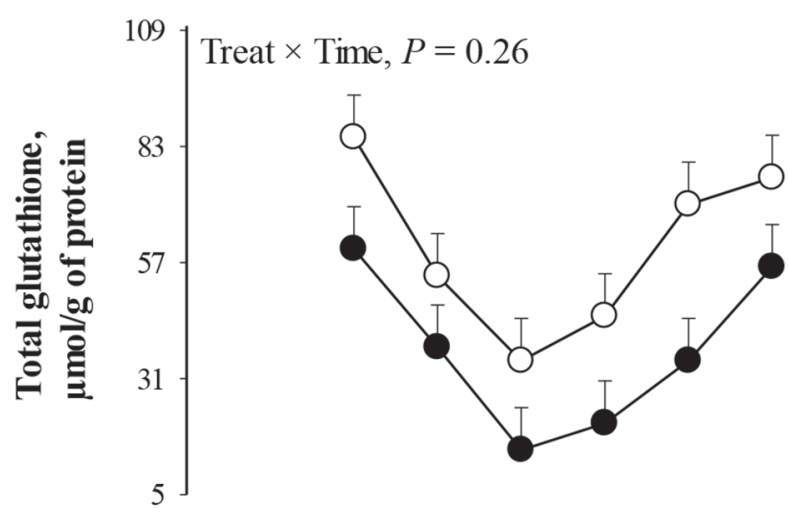

$\mathbf{F}$

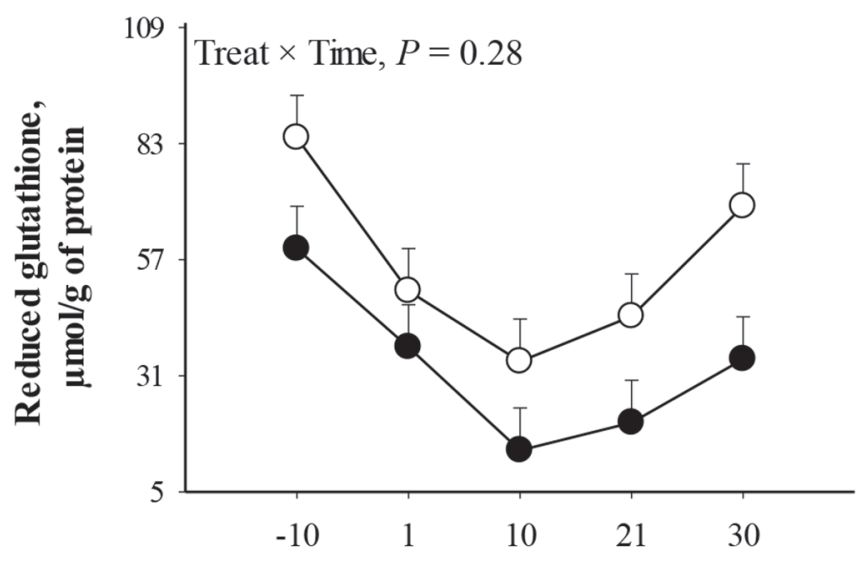

Day relative to parturition

Figure 3. Effect of ethyl-cellulose rumen-protected methionine (RPM) supplementation to multiparous Holstein cows from -28 through 60 DIM on plasma and liver biomarkers of oxidative stress $[\mathrm{A}=$ ferric-reducing ability of plasma (FRAP); $\mathrm{B}=$ reactive oxygen metabolites (ROM); $\mathrm{C}=\beta$-carotene; $\mathrm{D}=$ tocopherol; $\mathrm{E}=$ total glutathione; $\mathrm{F}=$ reduced glutathione]. Values represent the means $\pm \mathrm{SEM}$. The data from $\mathrm{d}-30$ were included as reference. Treat $=$ treatment. 
Table 4. Effects of ethyl-cellulose rumen-protected methionine (RPM) supplementation to multiparous Holstein dairy cows during the close-up (from $-28 \mathrm{~d}$ to parturition), fresh (from 1 to $30 \mathrm{DIM}$ ), and highproducing (from 31 to 60 DIM) periods on blood neutrophil and monocyte function

\begin{tabular}{|c|c|c|c|c|c|c|}
\hline \multirow[b]{2}{*}{ Item } & \multirow[b]{2}{*}{ Control } & \multirow[b]{2}{*}{ RPM } & \multirow[b]{2}{*}{ SEM } & \multicolumn{3}{|c|}{$P$-value } \\
\hline & & & & Treatment $^{1}$ & Time & Treatment $\times$ time \\
\hline \multicolumn{7}{|l|}{ Neutrophils } \\
\hline Phagocytosis & 49.7 & 59.4 & 3.07 & 0.04 & 0.25 & 0.77 \\
\hline Oxidative burst & 44.6 & 53.1 & 3.92 & 0.06 & 0.38 & 0.85 \\
\hline \multicolumn{7}{|l|}{ Monocytes } \\
\hline Phagocytosis & 43.9 & 48.1 & 2.95 & 0.12 & 0.12 & 0.59 \\
\hline Oxidative burst & 25.2 & 24.5 & 2.84 & 0.21 & 0.22 & 0.87 \\
\hline
\end{tabular}

${ }^{1}$ Ethyl-cellulose rumen-protected methionine effect.

Compared with controls, cows supplemented with ethyl-cellulose RPM had higher concentrations of total glutathione and reduced glutathione in plasma $(P<$ 0.01 ; Figure 3$)$. These data reinforce the conclusion that cows fed ethyl-cellulose RPM experienced less oxidative
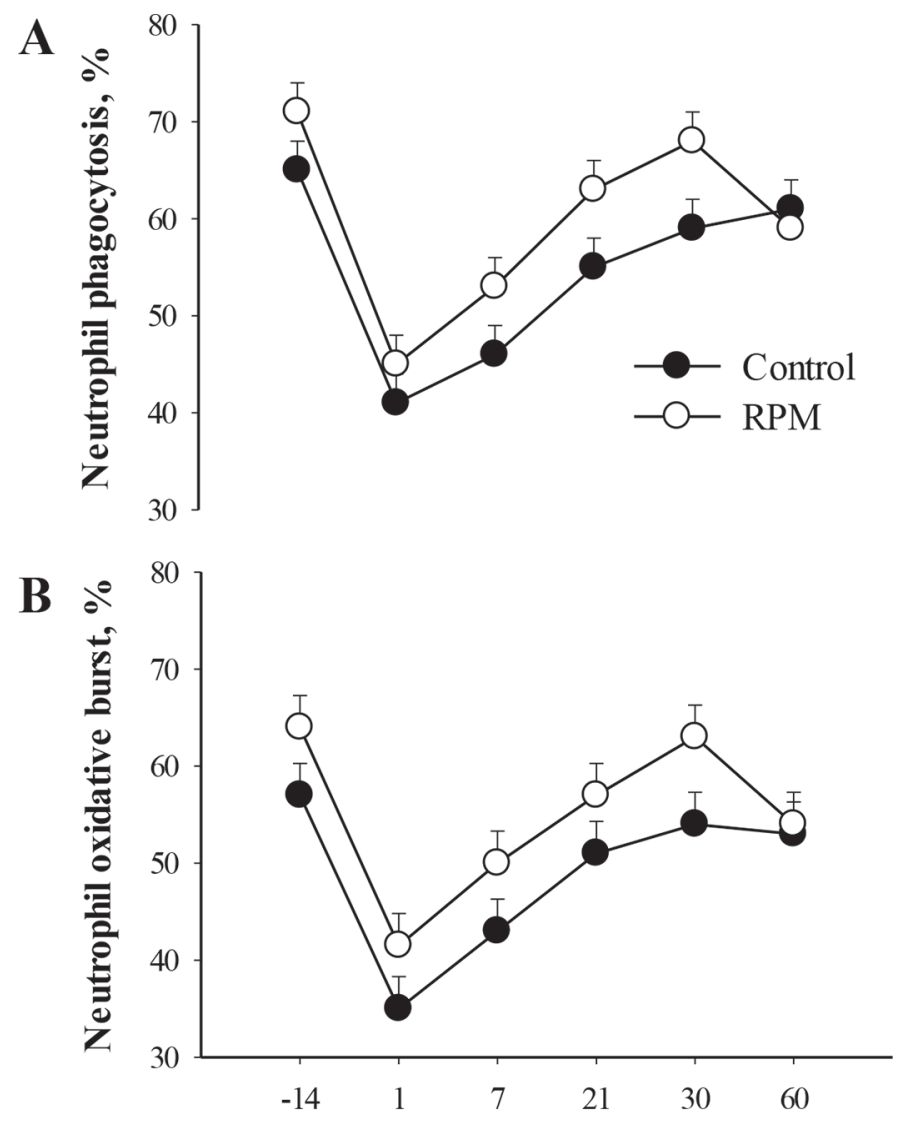

Day relative to parturition

Figure 4. Effect of ethyl-cellulose rumen-protected methionine (RPM) supplementation to multiparous Holstein cows from -28 through 60 DIM on neutrophil phagocytosis (A) and oxidative burst (B). Values represent the means \pm SEM. stress. Glutathione performs a vital function quenching free radicals and detoxifying xenobiotics (Wu et al., 2004). The GSH produced in liver can be used within the hepatic tissue or exported into the circulation, where it can aid in the control of systemic oxidative stress. Taken together, our results underscore the importance of methionine as a key player in the oxidative stress response, acting as a scavenger of ROM as previously observed in vitro (Campbell et al., 2016), and in dairy cows during the periparturient period (Osorio et al., 2014; Sun et al., 2016; Zhou et al., 2016a).

\section{In Vitro Whole-Blood Phagocytosis and Oxidative Burst}

Main effects of ethyl-cellulose RPM, time, and interactions on in vitro whole-blood phagocytosis and oxidative burst are reported in Table 4 . Upon in vitro Escherichia coli challenge, a greater $(P=0.04)$ increase in neutrophil phagocytosis capacity was detected in cows supplemented with ethyl-cellulose RPM (Table 4, Figure 4). Furthermore, compared with control cows, ethyl-cellulose RPM-supplemented cows tended to have greater blood neutrophil oxidative burst $(P=0.06)$. In contrast, monocyte phagocytosis and oxidative burst did not change in response to ethyl-cellulose RPM supplementation $(P \geq 0.12)$. Neutrophils and macrophages are the first line of defense of the innate immune system by phagocytosing, killing, and digesting invading pathogens. Because the activation of the immune system is an energy-dependent process, the greater DMI in ethyl-cellulose RPM (Batistel et al., 2017) could have contributed, at least in part, to the observed response in neutrophils. Furthermore, the lower concentrations of ROM together with the similar concentration of myeloperoxidase in ethyl-cellulose RPM cows could sustenance neutrophil function, as oxidative stress is detrimental to immune cells (Spears and Weiss, 2008).

Little evidence exists demonstrating that methionine per se alters immune function. However, the biologic 
effect on immune function from the total quantity of Met supplied is supported by the immunomodulatory capacity of its metabolites (taurine, GSH, and homocysteine; Grimble, 2006). For instance, in vivo models have demonstrated that taurine supplementation enhanced neutrophil phagocytic and bactericidal capacity (Masuda et al., 1984), whereas GSH helped sustain the oxidative burst response (Yan et al., 2012). Taken together, the present and previous data (Zhou et al., 2016a) underscore the role of Met on neutrophil function in periparturient cows.

\section{CONCLUSIONS}

Overall, the changes observed in plasma biomarkers indicate that feeding ethyl-cellulose RPM to achieve a ratio of 2.8:1 Lys to Met during the periparturient period and early lactation is an effective approach to help mitigate oxidative stress and inflammation as well as enhance liver and neutrophil function. Our results indicated that the positive effect on postpartal cow performance was likely due, at least in part, to a better immune response. Additional studies to evaluate this potential effect are warranted.

\section{ACKNOWLEDGMENTS}

Fernanda Batistel was supported by a fellowship from Coordenação de Aperfeiçoamento de Pessoal de Nível Superior (CAPES, Brazilian Ministry of Education, Brasília, Brazil) and by Hatch funds under project ILLU-538-914, National Institute of Food and Agriculture (Washington, DC). We thank Perdue AgriBusiness (Salisbury, MD) for the donation of ProVAAl AADvantage during the course of the experiment.

\section{REFERENCES}

Aschenbach, J. R., N. B. Kristensen, S. S. Donkin, H. M. Hammon, and G. B. Penner. 2010. Gluconeogenesis in dairy cows: The secret of making sweet milk from sour dough. IUBMB Life 62:869-877.

Batistel, F., J. M. Arroyo, A. Bellingeri, B. Saremi, C. Parys, E. Trevisi, F. Cardoso, and J. J. Loor. 2017. Ethyl-cellulose rumenprotected methionine enhances performance during the periparturient period and early lactation in Holstein cows. J. Dairy Sci. 100:7455-7467.

Benzie, I. F., and J. J. Strain. 1996. The ferric reducing ability of plasma (FRAP) as a measure of "antioxidant power": The FRAP assay. Anal. Biochem. 239:70-76.

Bertoni, G., A. Minuti, and E. Trevisi. 2015. Immune system, inflammation and nutrition. Anim. Prod. Sci. 55:354-360.

Bertoni, G., E. Trevisi, X. Han, and M. Bionaz. 2008. Effects of inflammatory conditions on liver activity in puerperium period and consequences for performance in dairy cows. J. Dairy Sci. 91:33003310 .

Bertoni, G., E. Trevisi, and F. Piccioli-Cappelli. 2004. Effects of acetyl-salicylate used in post-calving of dairy cows. Vet. Res. Commun. 28:217-219.
Bionaz, M., E. Trevisi, L. Calamari, F. Librandi, A. Ferrari, and G. Bertoni. 2007. Plasma paraoxonase, health, inflammatory conditions, and liver function in transition dairy cows. J. Dairy Sci. 90:1740-1750.

Bradford, B. J., K. Yuan, J. K. Farney, L. K. Mamedova, and A. J. Carpenter. 2015. Invited review: Inflammation during the transition to lactation: New adventures with an old flame. J. Dairy Sci. 98:6631-6650.

Brosnan, J. T., and M. E. Brosnan. 2006. The sulfur-containing amino acids: An overview. J. Nutr. 136:1636S-1640S.

Campbell, K., J. Vowinckel, M. A. Keller, and M. Ralser. 2016. Methionine metabolism alters oxidative stress resistance via the pentose phosphate pathway. Antioxid. Redox Signal. 24:543-547.

Chovatiya, R., and R. Medzhitov. 2014. Stress, inflammation, and defense of homeostasis. Mol. Cell 54:281-288.

Cray, C., J. Zaias, and N. H. Altman. 2009. Acute phase response in animals: A review. Comp. Med. 59:517-526.

Dann, H. M., D. E. Morin, G. A. Bollero, M. R. Murphy, and J. K. Drackley. 2005. Prepartum intake, postpartum induction of ketosis, and periparturient disorders affect the metabolic status of dairy cows. J. Dairy Sci. 88:3249-3264.

Drackley, J. K. 1999. ADSA Foundation Scholar Award. Biology of dairy cows during the transition period: The final frontier? J. Dairy Sci. 82:2259-2273.

Drackley, J. K., T. R. Overton, and G. N. Douglas. 2001. Adaptations of glucose and long-chain fatty acid metabolism in liver of dairy cows during the periparturient period. J. Dairy Sci. 84:E100-E112.

Ferré, N., J. Camps, E. Prats, E. Vilella, A. Paul, L. Figuera, and J. Joven. 2002. Serum paraoxonase activity: A new additional test for the improved evaluation of chronic liver damage. Clin. Chem. $48: 261-268$.

Grimble, R. F. 2006. The effects of sulfur amino acid intake on immune function in humans. J. Nutr. 136:1660S-1665S.

Grossi, P., G. Bertoni, F. P. Cappelli, and E. Trevisi. 2013. Effects of the precalving administration of omega-3 fatty acids alone or in combination with acetylsalicylic acid in periparturient dairy cows. J. Anim. Sci. 91:2657-2666.

Humblet, M. F., H. Guyot, B. Boudry, F. Mbayahi, C. Hanzen, F. Rollin, and J. M. Godeau. 2006. Relationship between haptoglobin, serum amyloid A, and clinical status in a survey of dairy herds during a 6-month period. Vet. Clin. Pathol. 35:188-193.

Masuda, M., K. Horisaka, and T. Koeda. 1984. Role of taurine in neutrophil function. Nippon Yakurigaku Zasshi 84:283-292.

Medzhitov, R. 2008. Origin and physiological roles of inflammation. Nature 454:428-435.

NRC. 2001. Nutrient Requirements of Dairy Cattle. 7th rev. ed. Natl. Acad. Press, Washington, DC.

Osorio, J. S., P. Ji, J. K. Drackley, D. Luchini, and J. J. Loor. 2013. Supplemental Smartamine M or MetaSmart during the transition period benefits postpartal cow performance and blood neutrophil function. J. Dairy Sci. 96:6248-6263.

Osorio, J. S., E. Trevisi, P. Ji, J. K. Drackley, D. Luchini, G. Bertoni, and J. J. Loor. 2014. Biomarkers of inflammation, metabolism, and oxidative stress in blood, liver, and milk reveal a better immunometabolic status in peripartal cows supplemented with Smartamine M or MetaSmart. J. Dairy Sci. 97:7437-7450.

Overton, T. R., D. W. LaCount, T. M. Cicela, and J. H. Clark. 1996. Evaluation of a ruminally protected methionine product for lactating dairy cows. J. Dairy Sci. 79:631-638.

Owen, J. A., F. C. Better, and J. Hoban. 1960. A simple method for the determination of serum haptoglobins. J. Clin. Pathol. 13:163164

Reynolds, C. K., P. C. Aikman, B. Lupoli, D. J. Humphries, and D. E. Beever. 2003. Splanchnic metabolism of dairy cows during the transition from late gestation through early lactation. J. Dairy Sci. $86: 1201-1217$.

Scheller, J., A. Chalaris, D. Schmidt-Arras, and S. Rose-John. 2011. The pro- and anti-inflammatory properties of the cytokine interleukin-6. Biochim. Biophys. Acta 1813:878-888.

Schwab, C. G. 1995. Protected proteins and amino acids for ruminants. Pages 115-141 in Biotechnology in Animal Feeds and Ani- 
mal Feeding. R. J. Wallace and A. Chesson, ed. VCH Veragsgesellschafe, Weinheim (Federal Republic of Germany) and VCH Publishers Inc., New York, NY.

Skinner, J. G., R. A. Brown, and L. Roberts. 1991. Bovine haptoglobin response in clinically defined field conditions. Vet. Rec. 128:147-149.

Sordillo, L. M. 2016. Nutritional strategies to optimize dairy cattle immunity. J. Dairy Sci. 99:4967-4982.

Sordillo, L. M., and S. L. Aitken. 2009. Impact of oxidative stress on the health and immune function of dairy cattle. Vet. Immunol. Immunopathol. 128:104-109.

Spears, J. W., and W. P. Weiss. 2008. Role of antioxidants and trace elements in health and immunity of transition dairy cows. Vet. J. 176:70-76

Sun, F., Y. Cao, C. Cai, S. Li, C. Yu, and Y. Yao. 2016. Regulation of nutritional metabolism in transition dairy cows: Energy homeostasis and health in response to post-ruminal choline and methionine. PLoS One 11:e0160659.

Sunderman, F. W., Jr., and S. Nomoto. 1970. Measurement of human serum ceruloplasmin by its p-phenylenediamine oxidase activity. Clin. Chem. 16:903-910.

Trevisi, E., M. Amadori, S. Cogrossi, E. Razzuoli, and G. Bertoni. 2012. Metabolic stress and inflammatory response in high-yielding, periparturient dairy cows. Res. Vet. Sci. 93:695-704.

Trevisi, E., P. Grossi, F. P. Cappelli, S. Cogrossi, and G. Bertoni. 2011. Attenuation of inflammatory response phenomena in periparturient dairy cows by the administration of an omega 3 rumen protected supplement containing vitamin E. Ital. J. Anim. Sci. $10: 277-285$.
Trevisi, E., L. Moscati, and M. L. Amadori. 2016. Disease-predicting and prognostic potential of innate immune responses to noninfectious stressors: Human and animal models. Pages 209-235 in The Innate Immune Response to Non-infectious Stressors. M. Amadori, ed. Elsevier Inc., Amsterdam, the Netherlands.

Wu, G., Y. Z. Fang, S. Yang, J. R. Lupton, and N. D. Turner. 2004 Glutathione metabolism and its implications for health. J. Nutr. 134:489-492.

Xing, Z., J. Gauldie, G. Cox, H. Baumann, M. Jordana, X. F. Lei, and M. K. Achong. 1998. IL-6 is an antiinflammatory cytokine required for controlling local or systemic acute inflammatory responses. J. Clin. Invest. 101:311-320.

Yan, J., X. Meng, L. M. Wancket, K. Lintner, L. D. Nelin, B. Chen, K. P. Francis, C. V. Smith, L. K. Rogers, and Y. Liu. 2012. Glutathione reductase facilitates host defense by sustaining phagocytic oxidative burst and promoting the development of neutrophil extracellular traps. J. Immunol. 188:2316-2327.

Zhou, Z. O. Bulgari, M. Vailati-Riboni, E. Trevisi, M. A. Ballou, F. C Cardoso, D. N. Luchini, and J. J. Loor. 2016a. Rumen-protected methionine compared with rumen-protected choline improves immunometabolic status in dairy cows during the peripartal period. J. Dairy Sci. 99:8956-8969.

Zhou, Z., M. Vailati-Riboni, E. Trevisi, J. K. Drackley, D. N. Luchini, and J. J. Loor. 2016b. Better postpartal performance in dairy cows supplemented with rumen-protected methionine compared with choline during the peripartal period. J. Dairy Sci. 99:8716-8732. 